\title{
Comparative Evaluation of Gingival Depigmentation by Scalpel, Electrosurgery, and Laser: A 14 Months' Follow-up Study
}

Raghunathan Jagannathan ${ }^{1}$, Swaminathan Rajendran² ${ }^{2}$ Thodur Madapusi Balaji ${ }^{3}$, Saranya Varadarajan $^{4}$, Lakshmi Priya Sridhar ${ }^{5}$

\begin{abstract}
Aim and objective: The aim of the study was to compare three different techniques using scalpel, electrosurgery, and laser for gingival depigmentation in terms of pain, discomfort, duration of procedure, wound healing, and repigmentation.

Materials and methods: Thirty patients in the age range of 24-38 years were briefed about the surgical procedure and an informed consent was obtained and they were randomly allocated into three groups of 10 individuals ( 5 males and 5 females) each: those undergoing depigmentation with scalpel (group I), electrosurgery (group II), and diode lasers (Biolase) (group III). Individuals of all three groups were asked to describe the level of pain and discomfort by using the visual analog scale (VAS) 2 hours, 24 hours, and 1 week postoperatively. Further, the groups were compared based on duration of procedure, wound healing, and repigmentation at the end of 14 months.

Results: All the groups showed a decrease in the pain levels, which was statistically highly significant 1 week postoperatively when compared 24 hours postoperatively. There was a statistically significant difference in the pain levels between the scalpel, electrosurgery, and lasers groups after 24 hours $(p<0.001)$, with the lasers group demonstrating significantly less pain and discomfort. There was significant difference between the groups with respect to the duration of procedure, with less mean time for completion of the procedure observed for group III. Furthermore, less time for wound healing was observed in group III as compared to other groups. Total 8 out 10 patients in group I, 7 out of 10 patients in group II, and 2 out of 10 patients in group III showed repigmentation at the end of 14 months.

Conclusion: The rising concern for esthetic demand of an individual requires the removal of hyperpigmented gingival areas to create a confident and pleasing smile, which could be easily attained by using laser.

Clinical significance: Laser is an effective and fast tool that causes less pain, discomfort, faster healing, and delayed repigmentation compared with scalpel or electrosurgery for gingival depigmentation.

Keywords: Depigmentation, Electrosurgery, Laser, Prospective study, Scalpel.

The Journal of Contemporary Dental Practice (2020): 10.5005/jp-journals-10024-2934
\end{abstract}

\section{INTRODUCTION}

There are several factors that determine the beauty of an individual's smile. One of the most imperative but often overlooked factor is gingival esthetics that could significantly enhance the smile and confidence of the individual. Gingival esthetics is a decisive factor in smile design. ${ }^{1}$ Beauty of the smile mainly revolves around gingival zenith, ${ }^{2}$ but the color of the gingiva can significantly influence the outcome of the smile design especially in individuals with high lip line and gummy smile. ${ }^{3}$ The physiologically ideal color of the gingiva is salmon pink, which can vary depending upon the intensity and depth of melanin pigmentation that is more prominent in Asians and blacks compared to Caucasians. ${ }^{4}$ Pigmentation in the gingiva and oral cavity could be physiological or pathological and affected by a plethora of local and systemic factors like use of tobacco products and long-term use of certain medications like antimalarial medication or antidepressants. ${ }^{5}$ The physiological color of gingiva is due to a combination by different types of pigments like melanoid, carotene, reduced hemoglobin, soft keratin, and oxyhemoglobin. ${ }^{6}$ Hyperpigmentation of the gingival tissues occurs when melanocytes deposit excessive amount of melanin concentrated mostly to the basal and suprabasal cell layers of the epithelium. ${ }^{7}$ Gingival color is not uniform and varies from person to person and it has been observed that hyperpigmentation is normally found in individuals of African, East Asian, or Hispanic ethnicity. ${ }^{8}$ Positive correlation of
1Department of Periodontics, Tagore Dental College and Hospital, Chennai, Tamil Nadu, India

${ }^{2}$ Department of Periodontics, Craniofacial Dental Clinic, Chennai, Tamil Nadu, India

${ }^{3}$ Department of Dentistry, Bharathirajaa Hospital and Research Centre, Chennai, Tamil Nadu, India

${ }^{4}$ Department of Oral Pathology and Microbiology, Sri Venkateswara Dental College and Hospital, Chennai, Tamil Nadu, India

${ }^{5}$ Department of Pedodontics and Preventive Dentistry, Tagore Dental College and Hospital, Chennai, Tamil Nadu, India

Corresponding Author: Raghunathan Jagannathan, Department of Periodontics, Tagore Dental College and Hospital, Chennai, Tamil Nadu, India, Phone: +91 9884957327, e-mail: doctorraghunathan@ gmail.com

How to cite this article: Jagannathan R, Rajendran S, Balaji TM, et al. Comparative Evaluation of Gingival Depigmentation by Scalpel, Electrosurgery, and Laser: A 14 Months' Follow-up Study. J Contemp Dent Pract 2020;21(10):1159-1164.

Source of support: Nil

Conflict of interest: None

skin color and gingival pigmentation among a sample of South Indian population has been documented where the authors further

(O) The Author(s). 2020 Open Access This article is distributed under the terms of the Creative Commons Attribution 4.0 International License (https://creativecommons. org/licenses/by-nc/4.0/), which permits unrestricted use, distribution, and non-commercial reproduction in any medium, provided you give appropriate credit to the original author(s) and the source, provide a link to the Creative Commons license, and indicate if changes were made. The Creative Commons Public Domain Dedication waiver (http://creativecommons.org/publicdomain/zero/1.0/) applies to the data made available in this article, unless otherwise stated. 
state that the pigmentation was more in the attached gingiva and interdental papilla. ${ }^{6,9}$ Although gingival hyperpigmentation per say is not a disorder or disease, it poses an esthetic challenge for an individual with gummy smile. ${ }^{10}$ Various treatment strategies and protocols have been successfully employed for depigmentation of the gingiva such as use of a rotary bur or surgical scalpel to scrape the gingival epithelium, use of free gingival grafts, electrocautery, cryotherapy, local application of chemical agents, and soft tissue dental lasers. ${ }^{11-14}$ Although several studies suggest laser ablation as a preferred treatment for gingival depigmentation, ${ }^{15}$ there are contradictive reports on the repigmentation rate post laser ablation as compared to the traditional scalpel method. ${ }^{16}$ There still exists lacunae in this regard; hence, the aim of the study was to compare three different techniques using scalpel, electrosurgery, and laser for gingival depigmentation in terms of pain, discomfort, duration of procedure, would healing, and repigmentation.

\section{Materials and Methods}

Total 30 systemically and periodontally healthy individuals in the age range of 24-38 years with hyperpigmented gingiva were recruited for the study upon obtaining a written informed consent. The study was performed from May 2018 to March 2020 at Bharathirajaa Hospital and Research Institute, Chennai.

\section{Study Participants and Group Allocation}

Equal number of males and females were enrolled. The participants were randomly assigned in to three groups as follows: group I-10 individuals (5 males, 5 females) undergoing gingival depigmentation by surgical scalpel, group II-10 individuals ( 5 males, 5 females) undergoing gingival depigmentation by electrosurgery, group III-10 individuals (5 males, 5 females) undergoing gingival depigmentation by ezlase $940 \mathrm{~nm}$ dental soft tissue laser. The inclusion criteria: individuals with physiological hyperpigmentation of gingiva in relation to the maxillary anterior region from right canine to left canine, individuals with esthetic concerns, individuals with thick gingival biotype as per Claffey and Shanley classification ${ }^{17}$ (thick tissue biotype referred to as having a tissue thickness $\geq 2 \mathrm{~mm}$ upon transgingival probing), and good oral hygiene. The following individuals were excluded from the study: individuals under any medication, tobacco smokers or use of tobacco in any other form, systemically compromised patients, pathological pigmentation other than physiological pigmentation, pregnant and lactating women, history of periodontal treatment for past 6 months, and individuals with history of postsurgical keloid.

\section{Surgical Procedure}

\section{Depigmentation Using Acalpel}

Under aseptic conditions and local anesthesia with 1:2,00,000 adrenaline infiltration, the hyperpigmented gingival epithelium from the right maxillary canine to the left maxillary canine was scraped using no. 15 BP blade (Fig. 1). Utmost care and precision was taken to scrape only the gingival epithelium between the tip of the interdental papilla and the mucogingival junction. Complete hemostasis was achieved by applying direct pressure with sterile gauze.

\section{Depigmentation Using Electrosurgery}

Under aseptic conditions and with topical application of local anesthetic gel, the hyperpigmented gingival epithelium from the right maxillary canine to the left maxillary canine was removed using a loop electrode (Fig. 2). Care was taken to carefully remove any remnants of pigmented areas without causing burn injuries to the underlying tissues. The surgical site was constantly moistened with saline-soaked sterile gauze.

\section{Depigmentation Using Laser}

The depigmentation procedure was done with topical application of local anesthetics gel. A diode laser (Biolase) with settings of 940 $\mathrm{nm} 1.00 \mathrm{~W}$ power setting, pulse interval of $0.20 \mathrm{~ms}$, and pulse length $0.05 \mathrm{~ms}$ was delivered through a fiber-optic tip. The pigmented gingival epithelium was ablated using the direct contact mode in painting strokes (Fig. 3). Care was taken to scrape only the gingival epithelium between the tip of the interdental papilla on one end and the mucogingival junction on the other end. Protective equipment for the patient and operator was used during the laser procedure.

\section{Postoperative Care}

All patients were asked to continue routine oral hygiene procedures to maintain good oral hygiene without any trauma to the surgical site. All patients were prescribed paracetamol $650 \mathrm{mg}$ tablet twice a day after food and were advised to take it only if they experienced pain or discomfort. All patients were instructed to use $0.2 \%$ chlorhexidine mouthwash (diluted) twice a day at least 30 minutes after brushing. Patients were recalled 24 hours, 48 hours, at the end of 1st, 2nd, 3rd, 4th week, and 3, 6, 12, 14 months posttreatment to assess various clinical parameters.

\section{Clinical Parameters Recorded}

The oral hygiene index (simplified) ${ }^{18}$ was recorded for all participants prior to enrolment into the study to ensure good oral hygiene. Gingival pigmentation was assessed using the DummettGupta oral pigmentation index. ${ }^{19} \mathrm{~A}$ visual analog scale (VAS) was used to quantify pain levels and patient's discomfort during the procedure as previously used by Gupta et al. ${ }^{20}$ Each participant was asked to complete the VAS index cards-2 hours, 24 hours, and 1 week after the procedure. ${ }^{21}$ The healing in all the three groups was evaluated visually at end of 1st, 2 nd, 3rd, and 4th week using the hydrogen peroxide test. ${ }^{22}$ The area to be evaluated was dried and $3 \% \mathrm{H}_{2} \mathrm{O}_{2}$ was applied to the healing wound to assess for any bubble formation. The grades were as follows: (a) negative (-): no bubble formation (complete healing due to granulation tissue formation), (b) positive (+): bubble formation (incomplete healing due to incomplete granulation tissue formation). Two consecutive days in which the test result was graded negative was indicative of complete healing attributed to complete granulation tissue formation. ${ }^{22}$ Time taken to perform complete depigmentation for each patient was recorded from the point of application of local anesthesia to complete removal of pigmented areas in the surgical site. All 30 depigmentation procedures were performed by a single qualified operator. Wound healing was assessed by another blinded examiner unaware of the treatment method used.

\section{Results}

A statistical analysis was carried out using the Statistical Package for Social Sciences (SPSS Inc., Chicago, IL, version 21.0 for windows). For qualitative variables, mean and standard deviation were calculated. In the present study, out of the total 30 patients treated (age group 24-38 years), 15 were males and 15 were females. All the patients 

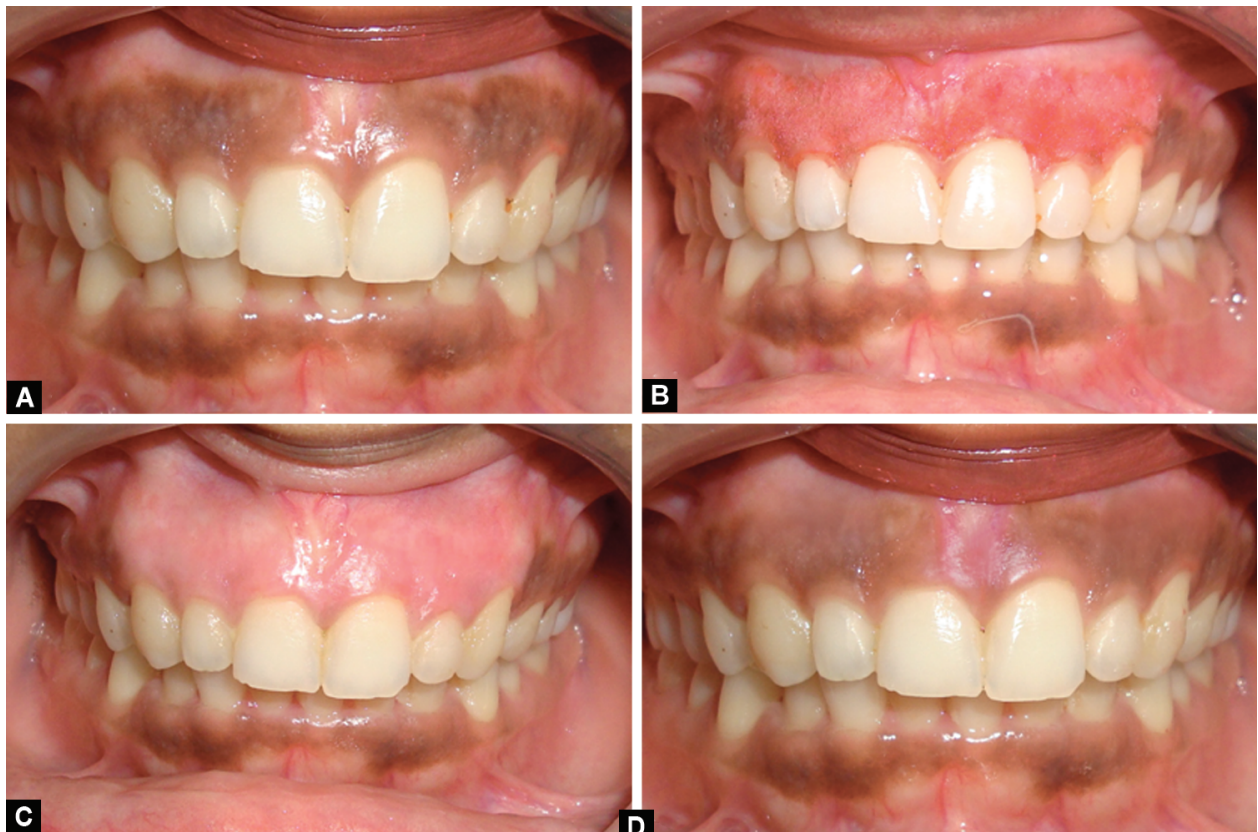

Figs 1 A to D: (A) Preoperative view of gingiva; (B) Immediate postoperative view of depigmentation by scalpel; (C) 1-year postoperative view; (D) Repigmentation after 14 months
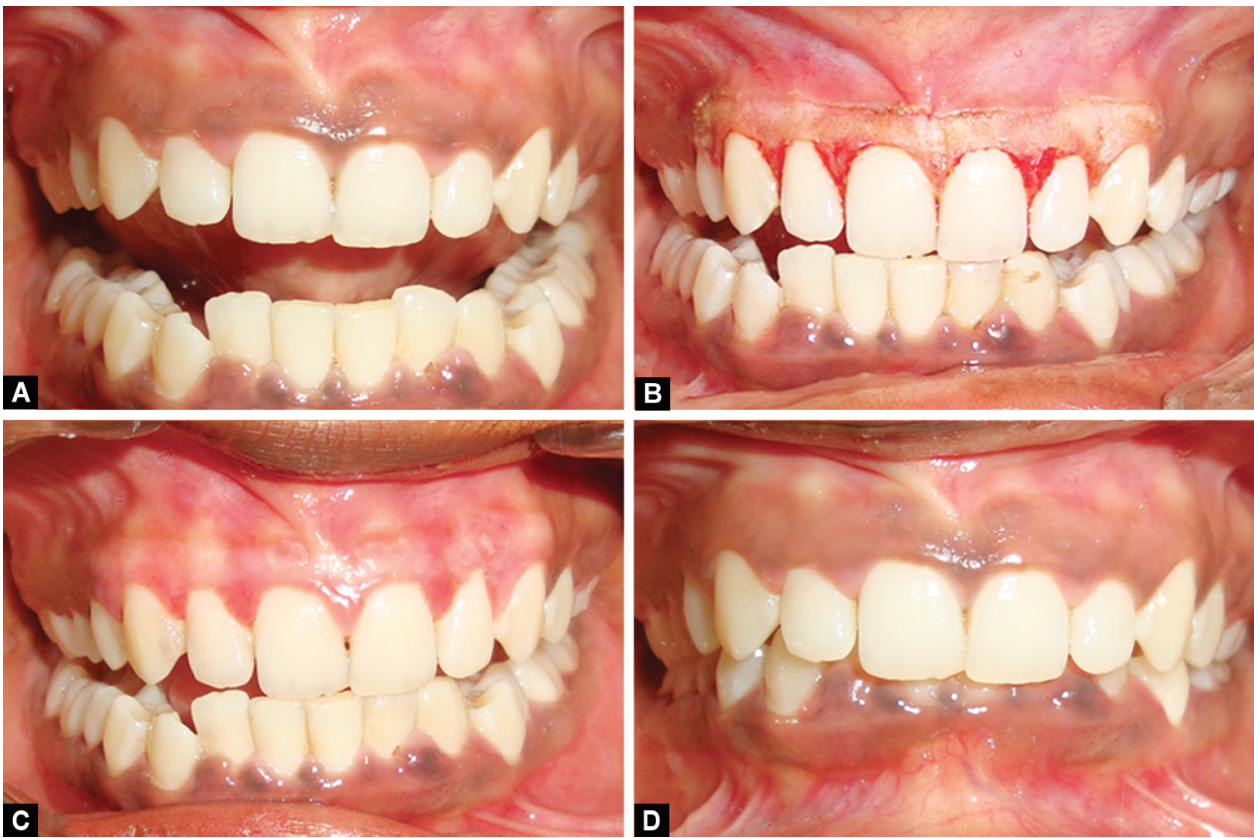

Figs 2A to D: (A) Preoperative view of gingiva; (B) Immediate postoperative view of depigmentation by electrosurgery; (C) 1-year postoperative view; (D) Repigmentation after 14 months

had good oral hygiene at baseline as assessed by the OHI-S index. Gingival pigmentation was assessed using the Dummett-Gupta oral pigmentation index and all patients has a uniform score of 3 at baseline. All patients tolerated the procedures well, but patients of group I and group II complained of pain initially days following the procedure, particularly while eating or drinking. The VAS scores of patients in all the groups are presented in Table 1 (scalpel), Table 2 (electrosurgery), and Table 3 (laser). The analysis showed a statistically significant difference in the pain levels between group I and group III 2 hours, 24 hours, and 1 week postoperatively ( $p<$ 0.001 , Student's $t$-test), with the laser group demonstrating less pain (Fig. 4). Group III demonstrated less pain and discomfort at all the time intervals compared to group I and group II. The average time taken to perform depigmentation in group I was 28 minutes and 30 seconds, in group II it was 17 minutes and 20 seconds, and in group III it was 15 minutes and 45 seconds. There was no significant difference in time taken for treatment between group II and group III, whereas compared to group I there was significant reduction in time taken to perform the treatment. Clinical evaluation of wound healing as assessed by the peroxide test is represented in Table 4. Postoperatively delayed healing was observed in the electrosurgically and scalpel-treated site. The peroxide test was 

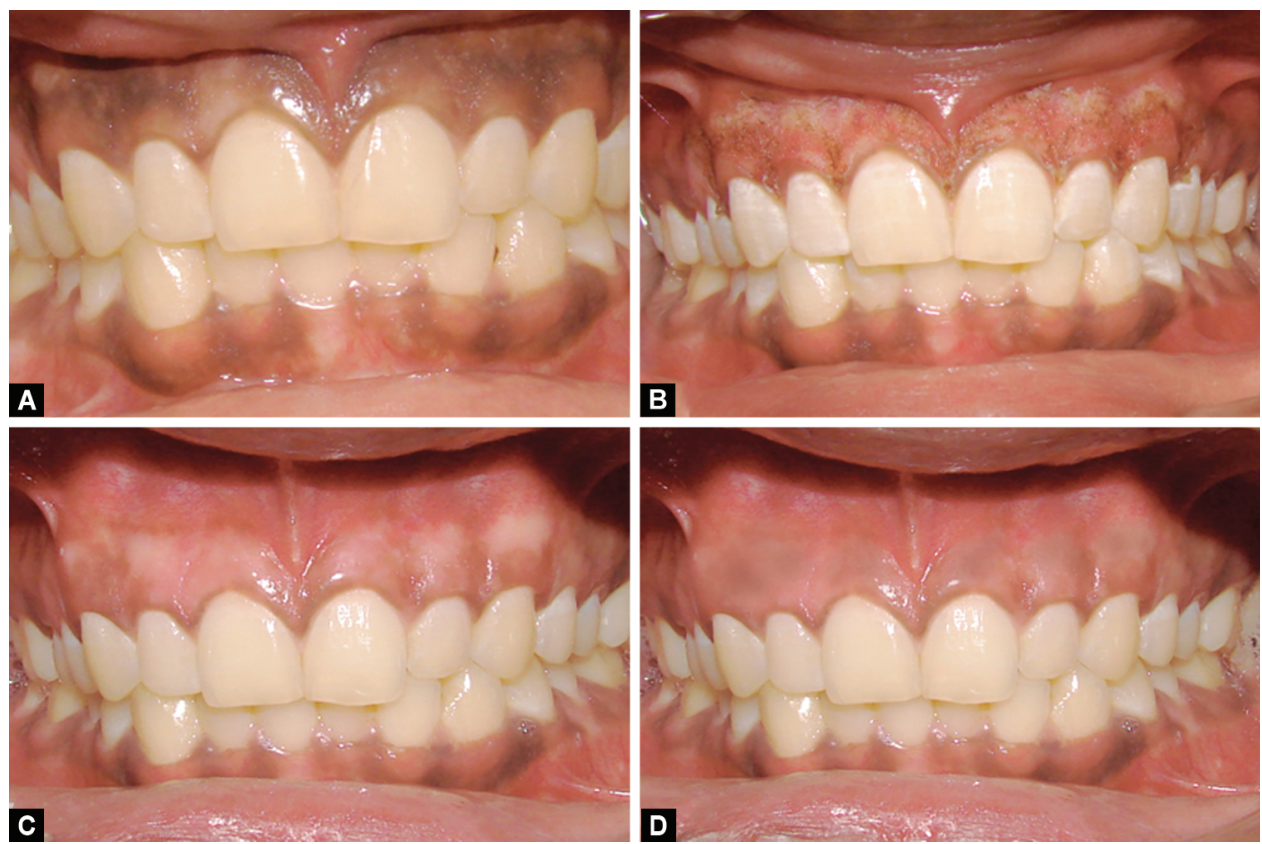

Figs 3A to D: (A) Preoperative view of gingiva; (B) Immediate postoperative view of depigmentation by laser; (C) 1-year postoperative view; (D) Repigmentation after 14 months

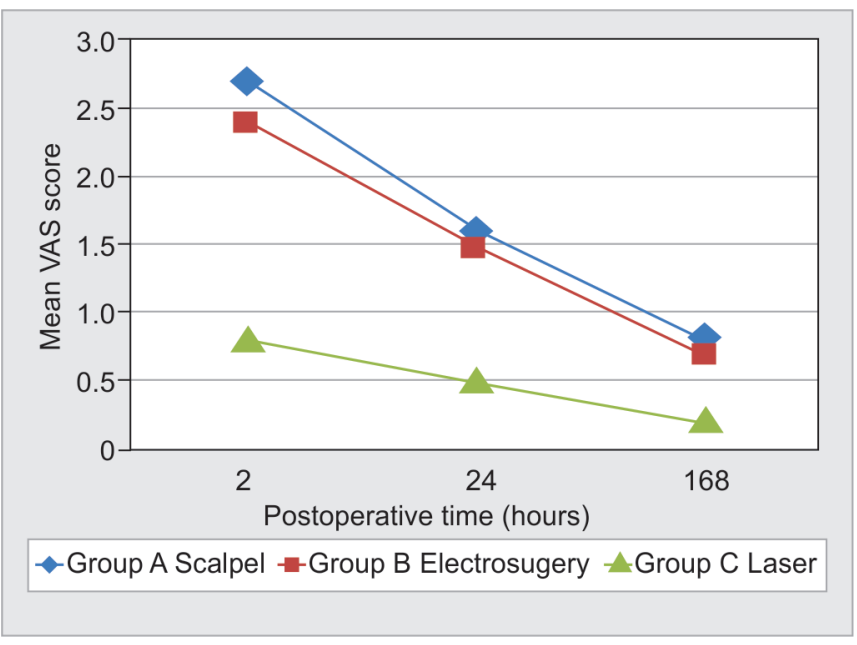

Fig 4: Comparison of mean visual analog scale (VAS) score of each group at 2 hours, 24 hours, and 1 week posttreatment

Table 1: Visual analog scale score of group I (scalpel)

\begin{tabular}{llll}
\hline $\begin{array}{l}\text { Patient serial } \\
\text { number }\end{array}$ & $\begin{array}{l}2 \text { hours } \\
\text { posttreatment }\end{array}$ & $\begin{array}{l}\text { 24 hours } \\
\text { posttreatment }\end{array}$ & $\begin{array}{l}1 \text { week } \\
\text { posttreatment }\end{array}$ \\
\hline 1 & 3 & 2 & 1 \\
2 & 4 & 2 & 1 \\
3 & 3 & 2 & 1 \\
4 & 4 & 3 & 1 \\
5 & 3 & 2 & 1 \\
6 & 3 & 1 & 0 \\
7 & 3 & 1 & 0 \\
8 & 2 & 1 & 1 \\
9 & 1 & 1 & 1 \\
10 & 1 & 1 & 1 \\
Total & 27 & 16 & 8 \\
\hline
\end{tabular}

Table 2: Visual analog scale score of group II (electrosurgery)

\begin{tabular}{llll}
\hline $\begin{array}{l}\text { Patient serial } \\
\text { number }\end{array}$ & $\begin{array}{l}2 \text { hours } \\
\text { posttreatment }\end{array}$ & $\begin{array}{l}24 \text { hours } \\
\text { posttreatment }\end{array}$ & $\begin{array}{l}1 \text { week } \\
\text { posttreatment }\end{array}$ \\
\hline 1 & 3 & 1 & 1 \\
2 & 2 & 2 & 1 \\
3 & 3 & 2 & 0 \\
4 & 2 & 1 & 1 \\
5 & 3 & 2 & 1 \\
6 & 3 & 1 & 0 \\
7 & 3 & 1 & 0 \\
8 & 2 & 2 & 1 \\
9 & 2 & 2 & 1 \\
10 & 1 & 1 & 1 \\
Total & 24 & 15 & 7 \\
\hline
\end{tabular}

Table 3: Visual analog scale score of group III (laser)

\begin{tabular}{llll}
\hline $\begin{array}{l}\text { Patient serial } \\
\text { number }\end{array}$ & $\begin{array}{l}\text { 2 hours } \\
\text { posttreatment }\end{array}$ & $\begin{array}{l}24 \text { hours } \\
\text { posttreatment }\end{array}$ & $\begin{array}{l}1 \text { week } \\
\text { posttreatment }\end{array}$ \\
\hline 1 & 1 & 1 & 1 \\
2 & 1 & 0 & 0 \\
3 & 1 & 0 & 0 \\
4 & 1 & 0 & 0 \\
5 & 1 & 1 & 0 \\
6 & 1 & 1 & 0 \\
7 & 0 & 0 & 0 \\
8 & 0 & 0 & 0 \\
9 & 1 & 1 & 0 \\
10 & 1 & 1 & 1 \\
Total & 8 & 5 & 2 \\
\hline
\end{tabular}

positive on 1st week and 2nd week postoperatively for both group I and group II (Table 4). After 1st week, slight redness was observed around the margins of the surgical site treated by a conventional 


\begin{tabular}{lllll}
\multicolumn{6}{l}{ Table 4: Clinical evaluation of wound healing among the three groups } \\
\hline Group & 1st week & 2nd week & 3rd week & 4th week \\
\hline I & + & + & - & - \\
II & + & + & - & - \\
III & + & - & - & - \\
\hline
\end{tabular}

+ bubbles present; - bubbles absent

technique whereas the site treated with electrosurgery showed generalized reddened areas. Better healing at laser-treated sites (group III) was clinically appreciable. Lesser time for healing in laser-treated sites (group III) could have contributed to decreased postoperative discomfort to the patients. All treated sites healed well after 1 month irrespective of treatment method used. Healed gingiva epithelium did not show signs of melanin pigmentation. Clinical examination of gingiva showed a pale pink appearance. All the patients were satisfied with the outcome. Total 8 out 10 patients in group I, 7 out of 10 patients in group II, and 2 out of 10 patients in group III showed repigmentation at the end of 14 months.

\section{Discussion}

Gingival melanin pigmentation can play a pivotal role in esthetic of an individual's smile. Many a time excessive pigmentation of the gingiva has physiological causes than pathological conditions. This has made the condition very prevalent in country like India where accentuated racial pigmentation is the most common complaint with which patients approach the dentist. Various periodontal plastic surgical techniques have been employed to remove gingival hyperpigmentation such as abrasion by bur, electrosurgery, cryosurgery, scalpel, and lasers. Even with the advancements in dental armamentarium, the use of surgical scalpel is still the preferred and more commonly used technique owing to its ease of use and economy compared to other techniques. ${ }^{22}$ However, the use of electrocautery and laser as techniques to achieve gingival depigmentation is also employed for their ease and advancement as a surgical technique. With regard to postoperative pain assessment, the VAS is a well-established tool despite its inbuilt demerits of being a subjective tool. ${ }^{23,24}$ The hydrogen peroxide test, which is a clinical maneuver to test complete epithelization of surgical wounds, was also followed in this study. The present study was performed with the prime aim of comparing three commonly employed techniques, namely scalpel, electrosurgery, and laser for depigmentation in patients who had accentuated physiological gingival pigmentation and also to compare the techniques based on pain, discomfort, duration of procedure, would healing, and repigmentation.

With regard to time taken for completing the procedure, it was found that the laser technique consumed the least time of 15 minutes 45 seconds compared to electrosurgery that consumed 17 minutes and 20 seconds and the scalpel technique that took 28 minutes and 30 seconds. This finding is justifiable as laser is an efficient technique to perform surgical procedures. It can be controlled well by the operator in comparison to the scalpel technique where the depth of penetration cannot be controlled. Also, bone charring and an offensive smell make electrocautery less acceptable than the laser technique. In this study, it was observed that there was not a significant procedural time difference when laser and electrosurgery techniques were compared with each other.
The postoperative pain was assessed at 2, 24, and 168 hours (1 week) in the present study. Findings revealed that the patients who underwent laser depigmentation had least postoperative pain at all the three assessment times using the VAS, which is a globally accepted pain scale.

The study demonstrated delayed epithelialization in scalpel and electrosurgically treated sites compared to laser, based on the hydrogen peroxide test. The connective tissue bed beneath the epithelium contains enzyme catalase, which upon interaction with $\mathrm{H}_{2} \mathrm{O}_{2}$ releases $\mathrm{H}_{2} \mathrm{O}$ and $\mathrm{O}_{2}$, which clinically represents as bubbling in the healing site. ${ }^{22}$ In situations where the epithelial barrier is intact, $\mathrm{H}_{2} \mathrm{O}_{2}$ does not reach the connective tissue bed and hence clinically there is no bubble formation. Studies comparing the healing of surgical would by scalpel and electrosurgery have shown to have conflicting results. Some studies showed no significant differences in gingival healing after electrosurgery and conventional scalpel surgery. Tipton et al. ${ }^{25}$ demonstrated that surgical would with a scalpel is stronger and heals faster than electrosurgically induced wound. Manivannan et al. ${ }^{26}$ stated that in electrosurgery sites there could be decreased blood flow contributing to delay in the healing process. The superior results obtained with regard to wound healing in the laser group can be in part explained by the beneficial effects of laser on many aspect of wound healing such as angiogenesis, stimulation of fibroblasts, epithelial cells, and inhibition of collagen degradation.

The success of a surgical procedure depends on the less recurrence rate of the condition treated. In this regards also, laser stood out as a technique with least reoccurrence rate of repigmentation of $20 \%$ in contrast to scalpel (80\%) and electrosurgery (70\%).

Laser is a noninvasive method that can be performed by application of topical local anesthetic gel. It causes minimum damage to the underlying hard tissues. Laser beam has the potential to destroy the epithelial cells up to the basal layer. This could probably reduce the rate of repigmentation as compared to other techniques. ${ }^{27}$ Laser beam targeted upon the pigmented lesions strike the melanocytes. Diode lasers are well absorbed by melanin and the light energy is converted to heat energy by photothermolysis. The diode lasers release their thermal effects by the hot tip effect due to accumulation of heat at the tip of the fiber; hence, the tip of the laser fiber is the cutting surface. Lasers also allow us to control the cutting efficiency as this is determined by the inherent ability to be absorbed within the chromophores with a specific target tissue and, thus, cause a tissue-specific ablation layer by layer and cell by cell. ${ }^{28}$ In the present study, the laser group patients reported less pain and discomfort compared with the electrosurgery group and the scalpel group. This can be attributed to the fact that diode laser can have an analgesic effect by disrupting the sodium and potassium pump in the cell membrane, thereby the impulses are not transmitted or merely due to the formation of a protein coagulum by ablation of the nerve endings. ${ }^{29}$ The advantages of lasers over other surgical techniques are: (a) ability to perform surgery with topical application of local anesthetic gel, (b) bloodless and dry surgical site, (c) immediate sterilization of the surgical site, (d) reduced mechanical trauma, minimal or no swelling, pain and scarring postoperatively. ${ }^{30}$

The limitation of the study is mainly the fact that a split-mouth design was not implemented to compare the three techniques of depigmentation. This can be justified as a split-mouth design would complicate the procedures and also consume more chairside time. Hence, it was not followed. 


\section{Conclusion}

The rising concern for esthetic demand of an individual requires the removal of hyperpigmented gingival areas to create a confident and pleasing smile, which could be easily attained by using laser. This study concludes that laser is an effective and fast tool that causes less pain, discomfort, faster healing, and delayed repigmentation compared with scalpel or electrosurgery for gingival depigmentation.

\section{References}

1. Goodlin R. Cosmetic dentistry-gingival aesthetics-a critical factor in smile design. Oral Health 2003;93:10-28.

2. Chu SJ, Tan JH, Stappert CF, et al. Gingival zenith positions and levels of the maxillary anterior dentition. J Esthet Restor Dent 2009;21(2):113-120. DOI: 10.1111/j.1708-8240.2009.00242.x.

3. Rufenacht CR. Principles of esthetic integration. Quintessence Publishing Company; 2000.

4. Hassell TM. Tissues and cells of the periodontium. Periodontol 2000 1993;3(1):9-38. DOI: 10.1111/j.1600-0757.1993.tb00230.x.

5. Granstein RD, Sober AJ. Drug- and heavy metal-induced hyperpigmentation. J Am Acad Dermatol 1981;5(1):1-18. DOI: 10.1016/ s0190-9622(81)70072-0.

6. Rakhewar PS, Patil HP, Thorat M. Identification of gingival pigmentation patterns and its correlation with skin color, gender and gingival phenotype in an Indian population. Indian J Multidiscip Dent 2016;6(2):87-92. DOI: 10.4103/2229-6360.197763.

7. Martini FH, Timmons MJ. Human Anatomy. Upper Saddle River, New Jersey: Prentice Hall Pub. Co.; 1995. p. 88-93.

8. Farnoosh AA. Treatment of gingival pigmentation and discoloration for esthetic purposes. Int J Periodont Restorat Dent 1990;10(4): 312-319.

9. Ponnaiyan D, Jegadeesan V, Perumal G, et al. Correlating skin color with gingival pigmentation patterns in South Indians - a cross sectional study. Oral Health Dent Manag 2014;13(1):132-136.

10. Hoexter DL. Periodontal aesthetics to enhance a smile. Dent Today 1999;18(5):78-81.

11. Lee K-M, Lee D-Y. A comparison of different gingival depigmentation techniques: ablation by erbium:yttrium-aluminum-garnet laser and abrasion by rotary instruments. J Periodontal Implant Sci 2011;41(4):201-207. DOI: 10.5051/jpis.2011.41.4.201.

12. Kaushik N, Srivastava N, Kaushik M, et al. Efficacy of different techniques of gingival depigmentation; a comparative evaluation with a case report. Int J Laser Dent 2013;3(2):68-72. DOI: 10.5005/ jp-journals-10022-1040.

13. Patil KP, Joshi V, Waghmode V, et al. Gingival depigmentation: a split mouth comparative study between scalpel and cryosurgery. Contemp Clin Dent 2015;6(Suppl 1):S97-S101. DOI: 10.4103/0976237X.152964.

14. Kaarthikeyan G, Jayakumar ND, Padmalatha O, et al. Pain assessment using a visual analog scale in patients undergoing gingival depigmentation by scalpel and $970 \mathrm{~nm}$ diode laser surgery. J Laser Dent 2012;20:20-23.

15. Azzeh MM. Treatment of gingival hyperpigmentation by erbiumdoped: yttrium, aluminum, and garnet laser for esthetic purposes. J Periodontol 2007;78(1):177-184. DOI: 10.1902/jop.2007.060167.

16. Sagar G, Rajesh N, Kumar T, et al. Comparative evaluation of two surgical techniques using conventional scalpel method and diode laser for treatment outcome of depigmentation: 6 months follow-up study. J Dent Lasers 2016;10(1):2-9. DOI: 10.4103/0976-2868.184600.

17. Claffey N, Shanley D. Relationship of gingival thickness and bleeding to loss of probing attachment in shallow sites following nonsurgical periodontal therapy. J Clin Periodontol 1986;13(7):654-657. DOI: 10.1111/j.1600-051x.1986.tb00861.x.

18. Greene JG, Vermillion JR. The simplified oral hygiene index. 1964;68((1):7-13.

19. Dummett CO, Sakumura JS, Barens $G$. The relationship of facial skin complexion to oral mucosa pigmentation and tooth color. J Prosthet Dent 1980;43(4):392-396. DOI: 10.1016/0022-3913(80)90207-3.

20. Gupta G, Kumar A, Khatri M, et al. Comparison of two different depigmentation techniques for treatment of hyperpigmented gingiva. J Indian Soc Periodontol 2014;18(6):705-709. DOI: 10.4103/0972-124X.147404.

21. Malkoc S, Buyukyilmaz T, Gelgor I, et al. Mucosal wound healing is impaired by examination stress. Psychosom Med 1998;60:362-365.

22. Bhusari BM, Kasat S. Comparison between scalpel technique and electrosurgery for depigmentation: a case series. J Indian Soc Periodontol 2011;15(4):402-405. DOI: 10.4103/0972-124X.92580.

23. Eslamian L, Borzabadi-Farahani A, Edini HZ, et al. The analgesic effect of benzocaine mucoadhesive patches on orthodontic pain caused by elastomeric separators, a preliminary study. Acta Odontol Scand 2013;71(5):1168-1173. DOI: 10.3109/00016357.2012.757358.

24. Eslamian L, Borzabadi-Farahani A, Hassanzadeh-Azhiri A, et al. The effect of $810 \mathrm{~nm}$ low-level laser therapy on pain caused by orthodontic elastomeric separators. Lasers Med Sci 2014;29(2): 559-564. DOI: 10.1007/s10103-012-1258-1.

25. Tipton WW, Garrick JG, Riggins RS. Healing of electrosurgical and scalpel wounds in rabbits. J Bone Joint Surg Am 1975;57(3):377-379. DOI: 10.2106/00004623-197557030-00016.

26. Manivannan N, Ahathya RS, Rajaram PC. Scalpel versus electrosurgery: comparison of gingival perfusion status using ultrasound Doppler flowmetry. J Pharm Bioallied Sci 2013;5(Suppl 2):S154-S159. DOI: 10.4103/0975-7406.114317.

27. Atsawasuwan $P$, Greethong $K$, Nimmanon $V$. Treatment of gingival hyperpigmentation for esthetic purposes by $\mathrm{Nd}$ : YAG laser: report of 4 cases. J Periodontol 2000;71(2):315-321. DOI: 10.1902/ jop.2000.71.2.315.

28. Lomke MA. Clinical applications of dental lasers. Gen Dent 2009;57(1):47-59.

29. Ohshiro T, Calderhead RG. Development of low reactive-level laser therapy and its present status. J Clin Laser Med Surg 1991;9(4):267275. DOI: 10.1089/clm.1991.9.267.

30. Wigdor HA, Walsh JTJr, Featherstone JD, et al. Lasers in dentistry. Lasers Surg Med 1995;16(2):103-133. DOI: 10.1002/lsm.1900160202. 